\title{
OS MÉTODOS DIDÁTICOS EMPREGADOS POR PROFESSORES DO ENSINO SUPERIOR: UM ESTUDO DE CASO NA LICENCIATURA E BACHARELADO EM EDUCAÇÃO FÍSICA
}

\author{
THE TEACHING METHODS EMPLOYED FOR TEACHERS OF HIGHER \\ EDUCATION: A CASE STUDY IN BACHELOR DEGREE AND BACHELOR \\ IN PHYSICAL EDUCATION
}

CONTREIRA, Clairton Balbueno clcontreira@yahoo.com.br Universidade Federal de Santa Maria

\author{
KRUG, Hugo Norberto \\ hnkrug@bol.com.br
} Universidade Federal de Santa Maria

\begin{abstract}
RESUMO Este estudo tem como objetivo identificar os métodos didáticos utilizados pelos professores de ensino superior nos cursos de Licenciatura e Bacharelado em Educação Física. A pesquisa é qualitativa do tipo estudo de caso. Utilizou-se a entrevista semiestruturada e análise de conteúdo para a coleta e exploração das informações. Participaram seis (6) docentes efetivos do Centro de Educação Física e Desportos da Universidade Federal de Santa Maria (CEFD/UFSM). Constatou-se que os entrevistados utilizam o saber experiencial como sendo um elemento fundamental em suas práticas de ensino. Através dele são obtidos os princípios básicos para a organização do trabalho pedagógico nas disciplinas, além disso, os conteúdos e contextualizações sofrem poucas modificações para exemplificarem suas diferentes aplicações em uma área ou outra, tanto pelos professores que adotam uma concepção/abordagem da Educação Física como os que não as utilizam em sua prática pedagógica.
\end{abstract}

Palavras-chave: Educação Física. Ensino Superior. Métodos Didáticos.

ABSTRACT This study has objective to identify the teaching methods used by teachers of higher education of the courses of Bachelor Degree and Bachelor in Physical Education. The research is qualitative of case study. Utilized a semistructured interview and content analysis to the collection and exploration of information. Participed six (6) teachers effective of the Center of Physical 
Education and Sports of Federal University of Santa Maria (CEFD/UFSM). It was found that the respondents utilized the experiential learning with being a fundamental element in their teaching practices. Through it is obtained the basic principles for the organization of educational work in the disciplines, moreover, the content and contextualization suffer few modifications for exemplify their different applications in one area or another, either by teachers who adopt a concept/approach of the Physical Education with the that not use it in their practice educational.

Keywords: Physical Education. Higher Education. Methods of Teaching.

\section{CONSIDERAÇÕES INICIAIS}

A estruturação do campo da docência na educação superior é algo relativamente recente, as discussões se intensificaram nesta área a partir da década de 1990, com a implantação dos processos avaliativos e, mais especificamente, da avaliação do corpo docente pelo discente, aliado à presença das tecnologias da informação e comunicação (VEIGA, 2006). De acordo com Cunha (2010), mesmo que recente como um espaço de produção de saberes, a pedagogia universitária vem se consolidando e legitimando nas ciências da educação. Tem mostrado que não basta o domínio de conhecimentos específicos para realizar a educação no ensino superior, pois a perspectiva tradicional de educação, não dá conta das demandas educativas contemporâneas. Hoje, mais que transmitir informações, o professor deve servir como ponte entre o conhecimento disponível, as estruturas cognitivas e afetivas dos alunos e do contexto histórico-cultural e político da sociedade.

Ainda Bolzan e Isaia (2010, p. 15) esclarecem que:

[...] a pedagogia universitária é entendida como um campo de aprendizagem da docência que envolve a apropriação de conhecimentos, saberes e fazeres próprios do magistério superior, estando vinculados à realidade concreta da atividade de ser professor em seus diversos campos de atuação e em seus respectivos domínios. Assim, o impulso que direciona a aprendizagem é representado por sentimentos que indicam a sua finalidade geral, bem como o estabelecimento de objetivos específicos, a partir da compreensão do ato educativo. 
Pode-se dizer que o docente que atua no ensino superior se depara com demandas de naturezas distintas, entre outros aspectos, abrangendo as seguintes dimensões: a) O social - deve aprender a intensificar as relações com os alunos abrangendo seus conhecimentos, vivências culturais, expectativa de vida, etc.; b) $\mathrm{O}$ institucional - deve participar ativamente dos rumos pedagógicos e políticos da universidade que se assemelhem aos saberes trabalhados em sala de aula; e; c) O pessoal - significa comprometerse com seu próprio percurso formativo e profissional, romper a cultura do isolamento e ampliar a convivência com os colegas em projetos integrados, em grupos de pesquisa e momentos de debates que permitem qualificar o seu trabalho (ALMEIDA, 2012). Ou seja, as atitudes dos docentes geralmente correspondem a uma proposta educativa na qual estão presentes as compreensões de homem, de sociedade, de mundo e de ciência construídos pelos professores. Estas representações podem repercutir de maneira direta ou indireta na atuação profissional, em momentos importantes que encaminham a estruturação dos processos metodológicos, na relação professor/aluno e na organização da disciplina (GRILLO, 2010).

Dessa forma, considerando esses pressupostos anteriores, direcionamos o nosso interesse investigativo para os métodos didáticos utilizados pelos professores de ensino superior, pois é necessário entendermos os rumos intencionais que a formação profissional está seguindo.

Neste sentido, entendemos que a Didática consiste nas ações educativas definidas pelos docentes através de seu caráter intencional, como também, de uma direção consciente de ensino visando à instrução dos indivíduos, capacitando-os para o domínio de instrumentos cognitivos e experiência sociocultural organizada, se ocupa dos processos de ensino aprendizagem e sua relação com a finalidade educativa (LIBÂNEO, 1994).

Ainda, Pimenta e Anastasiou (2012, p. 67) complementam esse conceito da seguinte forma:

[...] a didática diz, pois, das finalidades do ensinar dos pontos de vista político-ideológico (da relação entre conhecimento e poder, conhecimento e formação das sociedades), éticos (da relação 
conhecimento e formação humana, direitos, igualdade, felicidade, cidadania), psicopedagógicos (da relação entre conhecimento e desenvolvimento das capacidades de pensar e sentir, dos hábitos, atitudes e valores) e os propriamente didáticos (organização dos sistemas de ensino, de formação, das escolas, da seleção de

conteúdos de ensino, de currículos e organização dos percursos formativos, das aulas, dos modos de ensinar, da avaliação, da construção de conhecimentos).

Portanto, tem a sua ação na relação entre teoria e prática, engloba as contribuições de diferentes áreas científicas (educação, psicologia, sociologia, etc.) na intenção de operacionalizá-las, justificando um campo de estudos com identidade própria, não havendo outra disciplina do currículo de formação de professores que a substitua, razão pela qual é tida como uma disciplina integradora (LIBÂNEO, 1994).

A Didática busca proporcionar espaços de conhecimentos direcionados à compreensão das interações que ocorrem dentro da sala de aula, utilizando como base o contexto e as intenções formativas (LUCARELLI, 2007). Também cabe lembrar que além da finalidade prática, existe o caráter científico que a sustenta teoricamente. De acordo com Pimenta e Anastasiou (2012), é uma das áreas que integram a Pedagogia. Ocupa-se a investigar os fundamentos, as condições e os modos de realizar a educação mediante o ensino, vai se constituindo como uma ação histórica, sem a intencionalidade de criar regras e métodos, mas expandir a nossa compreensão das demandas que o ensino produz.

Segundo Mizukami (1986), há várias formas de se conceber o fenômeno educativo, pois não é uma realidade acabada que ocorre de forma única e exata em seus aspectos, as variadas relações estabelecidas com o ensino podem ser consideradas como mediações históricas que permitem realizar contextualizações e discussões críticas sobre seus aspectos. Na intenção de obter respostas para as ações dos professores que fundamentam seus métodos pedagógicos, a autora investiga sobre as diferentes tendências que influenciaram a educação no Brasil, trabalha com a seguinte classificação das abordagens: tradicional, comportamentalista, humanista, cognitivista e sociocultural. A referida autora esclarece que estas teorias não podem ser entendidas de maneira dicotomizada, mas sim que fossem realizadas 
reflexões, discussões e críticas entre elas para servirem de opções nas práticas dos docentes, evitando a sua utilização como apenas receituários estanques e externos aos professores.

De acordo com Azevedo e Shigunov (2001), as abordagens pedagógicas da Educação Física podem ser definidas como movimentos que buscam a renovação da teoria e da prática com o objetivo de estruturar o campo de conhecimentos que são específicos da Educação Física.

Desse modo, surge a seguinte questão que orienta esta investigação: os professores do CEFD/UFSM fazem uso de alguma concepção ou abordagem de ensino da Educação Física nos cursos de Licenciatura e Bacharelado?

Sendo assim, este estudo tem como objetivo identificar os métodos didáticos utilizados pelos professores de ensino superior nos cursos de Licenciatura e Bacharelado em Educação Física.

A pesquisa justifica-se devido ao fato de que há oito (8) anos o CEFD/UFSM reformulou seu currículo disponibilizando vagas para os cursos de Licenciatura e Bacharelado e, desse modo, consideramos ser um tempo suficiente para analisarmos seus impactos nos saberes docentes dos professores efetivos que possuem disciplinas em ambos os cursos. De acordo com Cunha (2010) a importância de compreender as iniciativas de construção de saberes docentes na educação superior ocorre pela falta de reconhecimento oficial sobre a sua legitimidade pedagógica, uma vez que não há legislação nesta direção, até mesmo a própria carreira no ensino superior, na grande maioria dos casos, está embasada em dispositivos ligados à produção científica decorrentes de pesquisas com pouca referência aos saberes necessários à docência. Entre as suas várias características, Tardif (2006) chama a atenção para o seguinte: o saber possui um sentido amplo que engloba os conhecimentos, as competências, as habilidades (ou aptidões) e as atitudes dos docentes, ou seja, aquilo que foi, muitas vezes, chamado de saber, de saber-fazer e de saber-ser.

\section{REVISITANDO OS SABERES DOCENTES}


A discussão sobre os saberes docentes surge em âmbito internacional nas décadas de 1980 e 1990. Entre alguns dos motivos que contribuíram para a sua emergência está o movimento de profissionalização do ensino e suas consequências para a questão do conhecimento dos professores em busca de um repertório, visando garantir a legitimidade da profissão, havendo a partir daí, uma ampliação tanto quantitativa, quanto, posteriormente, qualitativa deste campo (NUNES, 2001).

Tardif (2006) em sua obra "Saberes docentes e formação profissional", reflete criticamente sobre os enfoques tecnicistas e reducionistas de ensino perpetuados no mundo contemporâneo. $O$ autor analisa os processos sociológicos e psicológicos que constituem a atual sociedade, no intuito de buscar novas perspectivas para o trabalho docente a partir do reconhecimento do professor como um agente produtor de saberes. Aproxima o cotidiano profissional e a vida pessoal para pensar a formação de maneira que alcance os mais diversos aspectos que compõem a profissão.

Tardif (2006) elaborou a classificação dos saberes através das diferentes origens e manifestações no contexto educacional e são assim descritos pelo autor: a) Saberes da formação profissional - transmitidos pelas instituições de formação de professores, são saberes produzidos pelas ciências humanas e da educação, destinados à formação erudita dos docentes. Geralmente, os profissionais tomam contato com eles durante a formação inicial ou continuada; b) Saberes disciplinares - correspondem a diversos campos do conhecimento os quais emergem da tradição cultural de grupos produtores de saberes. Estão integrados nas universidades através de disciplinas dos cursos oferecidos para a formação inicial ou continuada; c) Saberes curriculares - correspondem às categorias de saberes sociais que a instituição de ensino elege como modelo de cultura e formação. Apresentam-se na forma de conteúdos, currículo e métodos que os professores devem dominar; e, d) Saberes experienciais - dizem respeito a um processo evolutivo em que o sujeito elabora métodos e técnicas de ação cuja natureza fundamenta-se em seu trabalho cotidiano, tanto individual quanto coletivo. Essas múltiplas articulações da prática docente fazem com que os professores 
dependam da capacidade de dominar e integrar tais saberes como condição de sua prática.

Sendo assim, constata-se que os saberes dos professores são manifestados de diferentes formas com diferentes origens, trazem em si o exercício do trabalho, utilizando o seu saber-fazer para resolver as situações que compreendem a docência, por esses motivos são considerados plurais ou heterogêneos.

\section{PROCEDIMENTOS METODOLÓGICOS}

A investigação é qualitativa sob a forma de estudo de caso. A pesquisa qualitativa surgiu como uma forma de reação ao modelo positivista/quantitativo, estando embasada nos referenciais teóricos marxistas, na fenomenologia e, ainda, no estrutural-funcionalismo. Sua preocupação fundamental é com a caracterização do fenômeno, com as formas com que se apresenta e suas variações, já que o principal objetivo é a descrição (TRIVINOS, 1987).

De acordo com Godoy (1995, p. 35) "o estudo de caso tem se tornado a estratégia preferida quando os pesquisadores procuram responder às questões 'como' e 'por que' certos fenômenos acontecem, quando há pouca possibilidade de controle".

A coleta das informações ocorreu através de entrevista semiestruturada. Para Lankshear e Knobel (2008, p. 174), "a entrevista semi-estruturada se caracteriza por incluir questões previamente preparadas, mas o pesquisador utilizará apenas como um guia, acompanhando os comentários importantes do entrevistado".

Foi utilizada a análise de conteúdo de Bardin (1977) como meio para examinar as informações obtidas nas entrevistas. A análise de conteúdo possui três etapas: 19) A pré-análise - envolve os primeiros contatos com os documentos de análise, a formulação de objetivos, a definição dos procedimentos a serem seguidos; $2^{\mathrm{a}}$ ) A exploração do material - corresponde ao cumprimento das decisões anteriormente tomada, isto é, leitura de documentos, categorização, entre outros; e, $3^{a}$ ) O tratamento dos resultados - 
onde os dados são lapidados, sendo que a interpretação deve ir além dos conteúdos expostos nos documentos, buscando descobrir o que está por trás do imediatamente apreendido.

Participaram da pesquisa seis (6) docentes efetivos do Centro de Educação Física e Desportos da UFSM, que representaram os diferentes departamentos existentes do curso: Departamento de Métodos e Técnicas Desportivas (DMTD), Departamento de Desportos Individuais (DDI), Departamento de Desportos Coletivos (DDC). A disponibilidade e o interesse em fazer parte da pesquisa foi o principal critério de escolha dos colaboradores.

A pesquisa contou com a participação de professores efetivos do curso do CEFD/UFSM, que possuem os títulos de doutorado e/ou mestrado na área da Educação Física e que atualmente trabalham em disciplinas de cunho teórico ou prático na Licenciatura e Bacharelado simultaneamente.

Cabe lembrar que os colaboradores tiveram a liberdade de deixar a qualquer momento a pesquisa sem nenhum dano de imagem. As suas identidades foram preservadas, de modo que, apenas os autores da pesquisa possuem conhecimento sobre elas. Foram identificados pelas letras iniciais do alfabeto (A, B, C, D, E, F).

\section{RESULTADOS E DISCUSSÕES}

\section{Perfil dos professores}

Professor A: possui graduação em Educação Física - Licenciatura Plena (1992) pelo CEFD/UFSM, especialização em Desenvolvimento Motor (1993), mestrado (1996) e doutorado (2001) em Ciência do Movimento Humano pela UFSM. Atualmente é docente na graduação e pós-graduação (em nível de especialização). Ministrou diversas disciplinas no antigo e novo currículo, tais como: Desenvolvimento Humano, Metodologia da Pesquisa, Medidas de Avaliação, Psicologia do Esporte e do Exercício e DCG de Ecoterapia. 
Desenvolve projetos de pesquisa, ensino e extensão nas áreas de Ecoterapia e Desenvolvimento Motor.

Professor B: possui graduação em Educação Física - Licenciatura Plena (1988) e especialização em Técnicas Desportivas (1990) pelo CEFD/UFSM, mestrado (1993) e doutorado (2002) em Educação Física pela Universidade Estadual de Campinas. Ministrou diversas disciplinas, tais como: Pedagogia da Educação Física Escolar, Grupo de Estudo Temático em Educação Física Escolar, Jogos Esportivos Coletivos II, Prática Educativa II e Voleibol. Realiza estudos na área da Educação Física, com ênfase em Praxiologia Motriz, formação de professores e didática dos esportes.

Professor C: possui graduação em Educação Física - Licenciatura Plena (1975) e especialização em Pesquisa e Ensino do Movimento Humano (1977) pelo CEFD/UFSM, mestrado em Educação Física pela Universidade Gama Filho (1990). Ministrou disciplinas na graduação e especialização em Educação Física Escolar: Laboratório de Atividades Esportivas Contemporâneas, Gestão de Eventos, Esporte e Cultura, Administração e Gestão do Esporte. Desenvolve estudos nas áreas de políticas públicas, gestão e esporte.

Professor D: possui graduação em Educação Física - Licenciatura Plena (1987), mestrado (1996) e doutorado (2002) em Ciência do Movimento Humano pelo CEFD/UFSM. Já ministrou disciplinas na graduação (Licenciatura e Bacharelado) e pós-graduação em nível de especialização e mestrado, tais como: Aprendizagem Motora, Prática Curricular, Avaliação do Movimento Humano, Aprendizagem e Desenvolvimento Motor. Realiza pesquisas na área da aprendizagem de habilidades motoras, dando uma atenção especial às capacidades perceptivo-motoras, diferentes informações e assimetrias laterais. As investigações são aplicadas no contexto da escola e fora dela, com diferentes populações.

Professor E: possui graduação em Educação Física - Licenciatura Plena pelo CEFD/UFSM (1979), especialização em Ginástica Rítmica Desportiva (1980) na Universidade Federal do Rio Grande do Sul, mestrado em Pedagogia do Movimento Humano (1991) pela Universidade Gama Filho e doutorado em Motricidade Humana (2002) na Universidade Técnica de Lisboa. Ministrou disciplinas em nível de graduação e especialização, tais como: Ginástica 
Rítmica, Dança, Ginástica de Competição, Pedagogia da Ginástica (DCG). Atualmente realiza pesquisas nos seguintes temas: dança, corporeidade, inclusão, Educação Física e movimento.

Professor F: possui graduação em Educação Física - Licenciatura Plena (1977) e mestrado em Ciência do Movimento Humano (1990) pelo CEFD/UFSM. Já ministrou diversas disciplinas, entre elas: História da Educação Física, do Esporte e Lazer em Educação Física, Bioética; Seminário em Estágio Supervisionado, História da Educação Física Geral, História da Educação Física Brasileira, Educação Psicomotora, Educação Física Escolar, Sociedade e Cultura. Realiza pesquisas nos seguintes temas: movimento, criança, idade escolar.

Nos perfis dos professores é possível perceber que todos os docentes estão há mais de (10) anos atuando no ensino superior, iniciaram suas atividades em quatro (4) décadas distintas: final dos anos 1970, início dos anos 1980, início dos anos 1990 e início dos anos 2000. Ao levarmos em consideração a classificação elaborada por Huberman (1995, p. 47) e observarmos o tempo de serviço de docência dos entrevistados, os mesmos, encontram-se nas quatro (4) últimas fases da carreira profissional. As fases são as seguintes:

1) a entrada na carreira (1 - 3 anos) - remete-se a uma sequência de estágios que envolvem o início da trajetória profissional. Inicialmente, passa pelo estágio denominado de 'sobrevivência' ou 'choque do real' que ocorre através da confrontação com a complexidade das situações que envolvem a docência, deflagrando o distanciamento dos ideais da realidade cotidiana do professor. Já o estágio de 'descoberta', condiz ao entusiasmo inicial pelo exercício da profissão, experiência vivida em paralelo com a 'sobrevivência', torna-se o aspecto que permite suportar a primeira;

2) a fase de estabilização (4 - 6 anos) - caracteriza-se pelo estado de comprometimento e tomada de responsabilidade da docência. O sujeito se reconhece como professor tornando-se mais independente e efetivo, afirma-se diante dos colegas e sociedade, elevando o seu sentimento de competência pedagógica, permitindo um estado de conforto com relação aos métodos de ensino adotados; 
3) a fase de diversificação (7 - 25 anos) - este momento é caracterizado pela inovação dos métodos de ensino aplicados pelos professores em sala de aula. Há uma tomada de consciência maior sobre o contexto educacional permitindo a realização de críticas ao funcionamento do sistema educativo, provocando o desejo de efetivar mudanças institucionais, pois se encontram com maior motivação para o desenvolvimento de reformas, como também, de buscar por novos desafios para evitar o surgimento de possíveis rotinas no cotidiano de suas atividades;

4) a fase de serenidade (25 - 35 anos) - trata-se muito mais de um 'estado de alma' do que uma fase de progressão da carreira. As pretensões dos professores com relação à profissão são menores, assim como o investimento que é realizado, em contra partida, a sensação de confiança e de serenidade aumenta. Não sentem necessidade de provar mais nada aos outros ou a si próprios. Os seus objetivos são traçados em termos mais reais com aquilo que é possível fazer dentro do contexto que está inserido;

5) a fase de conservantismo (25 - 35 anos) - ocorre paralelamente com a fase da serenidade, sendo que os professores estão mais propensos a realizarem queixas e reclamações sobre os alunos e suas atitudes, da política educacional, dos colegas mais jovens, da organização escolar etc. Chegam a esta fase por vários caminhos, principalmente por um questionamento prolongado e discordância com relação às reformas educacionais. É progressiva, mas se acelera a partir dos 50 anos de idade do docente; e,

6) a fase de desinvestimento (35 - 40 anos) - apresenta-se como um fenômeno controverso de natureza psicológica que tem como característica o recuo e a interiorização ao final da carreira profissional. Nesta fase os professores libertam-se progressivamente do trabalho para dedicarem um maior tempo a si próprio, a interesses exteriores à escola e as suas vidas sociais. Realizam reflexões mais profundas levando em consideração o tempo que ainda thes restam, provocando, muitas vezes, mudança de valores em virtude de suas satisfações pessoais.

Huberman (1995) lembra que os ciclos de vida profissional não são apenas um conjunto de acontecimentos e sim um processo que, para alguns, 
pode ser linear e, para outros, descontínuo. Não significa dizer que as sequências estabelecidas sejam experienciadas na mesma ordem e nos respectivos períodos, nada impede de um profissional retornar a uma das fases ou passar por uma delas e sofrer todos os seus efeitos. Desse modo, no decorrer da discussão, os professores entrevistados contribuíram com as suas vivências acumuladas ao longo da vida acadêmica, apresentando as opiniões sobre as diferentes questões que envolvem a docência universitária.

\section{Os professores do CEFD/UFSM e seus métodos didáticos}

A partir das falas dos participantes da investigação, constatou-se que existem alguns professores que trabalham com as denominadas concepções ou abordagens da Educação Física. Estas são utilizadas como base da organização pedagógica para o desenvolvimento de suas disciplinas, fazendo com que os conhecimentos interajam com os métodos condizentes com aquilo que acreditam ser a melhor opção de ensino e aprendizagem, mas existem, também, aqueles que não definem ou caracterizam uma concepção específica, desenvolvem suas atividades a partir daquilo que consideram ser essencial dentro da área de atuação e experiência docente. Inicialmente apresentaremos os professores que adotam uma abordagem específica no desenvolvimento do trabalho docente e posteriormente os que não enquadram os seus métodos em uma determinada concepção de ensino.

O professor B utiliza a Praxilogia Motriz como fonte teórica de suas ações educativas. Essa foi idealizada pelo professor francês Pierre Parlebas, no final da década de 1960 e tem como principal obra "Jeux, Sports et Sociétés: Lexique de Prexéologie Motrice", na qual o autor apresenta, em ordem alfabética, cada terminologia utilizada na teoria. Foi estruturada em sete (7) categorias: conceitos básicos, modelização, pedagógica, semiomotriz, sócio-institucional, decisão e interação. Não se constitui em uma concepção/abordagem, mas caracteriza-se como um conhecimento que utiliza critérios científicos para compreender as diferentes dinâmicas que envolvem as atividades físicas. Tem como ponto de partida o estudo da ação motriz, 
buscando a essência dos jogos e esportes independentemente de seus atores ou contexto. Segundo Ribas (2005) é parecido com o conhecimento de notas musicais que orientam o ensino da música, mas apenas conhecê-las não basta, é preciso ter uma meta, um projeto e um sentido. Consiste em um instrumento de compreensão do mundo dos jogos e esportes, essencialmente, do estudo de sua lógica interna.

Os modelos elaborados por Parlebas estão direcionados essencialmente ao estudo e compreensão dos jogos. Reúne uma série de elementos universais para explicar as diferentes ações que ocorrem dentro dos esportes, levando em consideração as regras que os orientam. Evidencia através de gráficos, cálculos matemáticos e esquemas a possibilidade de expressar com mais precisão a lógica interna dos jogos e esportes (RIBAS; ARAÚJO, 2008).

A praxiologia motriz é constituída por conceituações que correspondem a sete (7) diferentes níveis de interpretações produzidas pela lógica estrutural de uma situação motriz, são elas: a) Comunicação motriz - acontece através de interações cooperativas ou opositoras que ocorrem durante a realização dos jogos e esportes; b) Interação de marca - consiste nas ações que levaram o êxito ou fracasso dos sujeitos envolvidos em uma situação motriz; c) Sistema de pontuação - é um código que representa e informa os resultados motrizes; d) Papéis - são as diferentes funções assumidas pelos participantes com relação aos objetos, espaço e setores de ação numa determinada situação; e) Sub-papéis - consiste de uma ação, por menor que seja, demonstrando significado para quem observa o sujeito em interação motriz; f) Gestemas - são as comunicações gestuais, verbais que representam os sinais produzidos pelos participantes a fim de facilitar as interações durante a realização dos movimentos; e, g) Praxêmas - é a comunicação corporal e comportamental do sujeito que interage e estabelece a coordenação das ações dentro de um jogo ou esporte (RAMOS, 2000).

Ainda é importante ressaltar a 'conduta motriz', pois é considerada como o objeto da Educação Física Escolar, consiste na organização do comportamento motor levando o seu significado contextual, ou seja, em um esporte ou jogo não são apenas atletas se enfrentando com o objetivo de 
vencer um ao outro, mas existe uma série de sentidos, intenções e fatos que dão significado as suas ações.

Na fala do professor B observa-se a importância da Praxiologia para a prática de ensino:

[...] eu acabo fazendo a inserção da discussão da Praxiologia na disciplina de Voleibol. Inclusive, eu falo no início da disciplina que esta talvez seja a minha maior contribuição, que é a discussão da Praxiologia e a análise que ela trás dos jogos e esportes [...] isso é uma coisa que eu não abro mão, porque é um conhecimento que eles não vão ter em outro momento, é um conhecimento que só eu tenho tratado aqui dentro do CEFD (Professor B).

À medida que as aulas vão se desenvolvendo, o referido professor busca pontuar diversos elementos internos dos jogos e esportes, caracterizando as suas diferentes possibilidades, no intuito de que os alunos compreendam a dinâmica que envolve os seus conceitos dentro de uma perspectiva ampliada, não mais individualizada ou fragmentada, estabelecendo relações comuns entre eles.

Entende que a disciplina de Voleibol, contemplada nos dois cursos, não possui diferença nos conhecimentos trabalhados na Licenciatura ou no Bacharelado. De acordo com o professor, a base teórica que fundamenta o esporte são as mesmas, não existindo dois tipos de Voleibol. As mudanças metodológicas realizadas entre um curso e outro, condiz em um momento específico da disciplina, no qual, trata sobre a estruturação do ensino, focando para os contextos de atuação em cada uma das áreas. A partir daí, são realizadas adequações no conteúdo para atender as necessidades formativas específicas das turmas, pois os alunos de Licenciatura possuem uma bagagem maior de conhecimentos didáticos em relação aos alunos do Bacharelado, por esse motivo, no momento da reflexão sobre os métodos organizacionais do ensino, a abordagem utilizada pelo docente acaba sofrendo alterações entre os cursos.

O saber considerado pelo professor B como sendo essencial para a formação dos acadêmicos de ambos os cursos, está direcionado à organização 
do trabalho pedagógico. Independente da área de atuação, o aluno deve finalizar a graduação sabendo estruturar a sua práxis. Ter conhecimento dos diferentes métodos que fazem parte do corpo teórico da profissão, aplicando-os com propriedade, não importando a concepção escolhida, demonstrando condições de justificarem teoricamente a proposta elaborada.

O professor $\mathbf{C}$ relata que trabalha dentro das concepções históricocríticas de ensino. Tem origem nos movimentos renovadores da Educação Física. Caracterizam-se pela presença de princípios filosóficos em torno do ser humano, surgem como críticas às correntes oriundas da Psicologia e conhecimentos comportamentalistas. Entre elas, estão as seguintes abordagens progressistas críticas: Crítico-superadora, Crítico-emancipatória, Construtivista e Aulas Abertas.

Pelo discurso apresentado nas entrevistas, percebem-se elementos característicos da concepção crítico-superadora. Segundo Bracht (1999), a referida abordagem baseia-se na pedagogia histórico-crítica, elaborada por Demerval Saviani e um Coletivo de Autores, que foi apresentada para a área através da obra intitulada "Metodologia do ensino da Educação Física", publicada em 1992. Tem como objeto de estudo a cultura corporal concretizada nas suas diferentes representações (esporte, ginástica, jogos, lutas, dança e a mímica), propondo que este objeto de estudo seja tratado de forma historicizada, de maneira a ser apreendido em seus movimentos contraditórios.

Para Azevedo e Shigunov (2001), a referida concepção busca entender com profundidade o ensinar, que não significa apenas transferir ou repetir conhecimentos, mas criar as possibilidades de sua produção crítica, sobre a assimilação desses conhecimentos, valorizando a questão da contextualização dos fatos e do resgate histórico. Essa concepção é estruturada na forma de ciclos de escolarização, em que os conteúdos são desenvolvidos simultaneamente, ampliando o pensamento do aluno de maneira espiralada, buscando que ele interprete, compreenda e explique a realidade em que vive. São os seguintes: $1^{\circ}$ ) Organização da identidade dos dados da realidade; $2^{\circ}$ ) Iniciação à sistematização do conhecimento; $3^{\circ}$ ) Ampliação da sistematização do conhecimento; $4^{\circ}$ ) Aprofundamento da sistematização do conhecimento. 
O referido professor C realiza reflexões críticas durante as suas práticas pedagógicas em sala de aula, através de discussões dos conteúdos desenvolvidos tanto na Licenciatura quanto no Bacharelado. O faz com a ajuda das leituras sugeridas no cronograma da disciplina, como também, estimula a pesquisa de outros textos para ampliar os olhares dos alunos sobre os temas propostos, expandindo os seus leques de conhecimentos.

[...] busco que os alunos entendam sobre elementos que compõem a sociedade, entendam de educação, de competências, das atribuições que as diretrizes curriculares contemplam que os parâmetros curriculares contemplam, das políticas públicas de ensino [...] levanto questionamentos sobre a realidade do trabalho, quem está se apropriando da questão da cultura do movimento, das práticas corporais, do esporte, do lazer e da atividade física? Como é que era antes? Como é que é hoje? Qual é a premissa? Hoje a premissa é de todas as idades? É intergeracional? [...] (Professor C).

Esse professor entende que a Educação Física é uma só, não existe diferenças entre os cursos. Em sua concepção, a formação deve abranger todas as áreas do conhecimento. Busca trabalhar as questões que envolvem a área social e seus significados para a atuação profissional, seja na Licenciatura ou no Bacharelado. Esforça-se para utilizar os mesmos métodos didáticos nos cursos, mas percebe muita resistência das turmas do Bacharelado em receber novas formas de tratar os temas, por estarem acostumados ao método tradicional, tornando o ensino fragmentado, dificultando as suas ações pedagógicas dentro da disciplina. Segundo Mizukami (1986) no ensino tradicional todas as funções educativas estão centradas no professor, o aluno apenas executa as orientações que the são prescritas. O papel do professor se caracteriza pela garantia de que o conhecimento seja adquirido, independentemente do interesse ou vontade do aluno, no qual as oportunidades de participação social são limitadas.

Ainda, o professor $\mathbf{C}$ considera essencial que o aluno saiba reconhecer a importância das ciências sociais como parte inerente do seu trabalho, 
possibilitando que a formação ocorra dentro de um universo plural e não segmentado. Fazendo com que o graduando possa realizar uma leitura de mundo com mais coerência, entendendo que apenas a sua formação específica não é capaz de fornecer subsídios para a compreensão da educação como um todo.

Para o Coletivo de Autores (1992) o reconhecimento da relevância social do conteúdo, implica em compreender o seu sentido e significado, pois este deve estar vinculado à realidade concreta e oferecer subsídios para a elucidação do determinante sócio-histórico do aluno.

O professor $\mathbf{F}$ adota a concepção de ensino aberto de Educação Física como base de sua metodologia de ensino. Os responsáveis pela introdução desta abordagem no Brasil foram os professores alemães Reiner Hildebrandt e Ralf Laging, tendo como principal obra "Concepções Abertas no Ensino de Educação Física" de 1986. De acordo com Krug (2008) o significado das Aulas Abertas consiste na reflexão e análise do conceito de movimento no esporte e mundo de movimento. Quando se planeja nessa concepção é necessário ser flexível, aberto a várias possibilidades e experiências. O professor abdica de um planejamento rígido e do monopólio das decisões, oferecendo um espaço para as ações e decisões. Os alunos têm oportunidade de trazer, para a aula, imaginações, ideias e interesses, em relação a movimento, jogos, esporte e brincadeira, participando do planejamento e da construção da aula.

Segundo Hildebrandt e Laging (2005), a concepção de ensino aberto baseia-se na ideia de proporcionar ao aluno a possibilidade de decisão conjunta, levando em consideração o grau de co-decisão que será administrada pelo professor. O planejamento e execução das atividades previstas devem ser apresentados de maneira que existam espaços para que os alunos possam expressar as suas opiniões livremente.

De acordo com Bracht (1999), esta perspectiva pode ser analisada em termos de um 'continuum', indo de uma concepção fechada a uma concepção aberta de ensino. Considera que as abordagens fechadas inibem a formação de um sujeito autônomo e crítico, já essa proposta indica a abertura das aulas 
no sentido de estimular a participação dos alunos sobre as decisões didáticas que configuram as aulas.

A elaboração de situações é um aspecto central na formação do ensino aberto, pois durante o desenrolar das atividades são estimuladas as decisões em conjunto, cabendo ao professor a função de um orientador, no intuito de facilitar as trocas comunicativas. As situações podem ser iniciadas por estímulos, temas, questões ou tarefas e arranjo de aparelho. Os estímulos são solicitações curtas ou informações que servem para indicar os recursos de movimentos a serem utilizados na execução dos exercícios, privilegiando as atividades que envolvem a solução de problemas. As questões, temas e tarefas se complementam, não tem a função exclusiva de dar início às atividades, mas também de desenvolver o diálogo ou assumir função de observação. Os arranjos e aparelhos correspondem a recursos materiais que podem ser introduzidos na aula, apresentando solicitações não-verbais de movimento, podendo ser combinado com as outras situações.

É importante assinalar que dentro deste complexo de decisões, a participação de todos, tanto dos alunos quanto do professor, não deve se limitar a problemas motores, mas também abranger problemas sociais. As ações realizadas em aula são sempre indicadas pelo professor e os passos direcionados em função dos objetivos e, assim, os problemas sociais são encarados subjetivamente. Desse modo, a socialização possibilita as reflexões necessárias sobre a estruturação da aula e a representação dos papéis dos alunos (KRUG, 2008).

Tendo por base a referida abordagem o professor $\mathbf{F}$ desenvolve as suas disciplinas buscando maximizar as experiências dos alunos através das discussões desenvolvidas em sala de aula, como também, entende que eles devem ter mais participação em suas formações, aproveitando as oportunidades que o curso disponibiliza de uma maneira mais autônoma. Observam-se esses elementos na seguinte fala:

Em função de eu ter feito o mestrado e me aproximado de Hildebrandt, é o ensino aberto [...] eu nunca trato as minhas disciplinas com um rigor científico [...]. Eu sou muito liberal nas questões das disciplinas, nos últimos 
anos nem prova eu faço [...] no primeiro dia de aula eu digo aos meus alunos que o interesse deve ser na questão de ler, de compreender, de poder discutir e principalmente falar sobre estas coisas, porque uma maneira de você aprender é falar sobre estas coisas, do que necessariamente cobrar com provas, com notas, reprovar [...]. Para mim, isso é uma coisa resolvida, é uma coisa que não tenho mais interesse [...] acho que também é necessário colocar a responsabilidade sobre essa questão do aprender em cima dos alunos (Professor F).

O referido professor encontra dificuldades para implementar esse método em suas disciplinas, principalmente pela falta de participação dos alunos, pois as ações que fazem parte dessa concepção se colocam em oposição ao ensino tradicional, fortemente enraizados nas instituições escolares e superiores, provocando, muitas vezes, a inibição para expressarem suas opiniões. Além disso, lembra que fazer o aluno interagir utilizando os conceitos da abordagem, não quer dizer que a aprendizagem aconteça ao acaso, existe um planejamento prévio com objetivos a serem alcançados. Segundo Hildebrandt e Langing (2005), o ensino aberto também necessita de um planejamento, tal como o ensino fechado, mas existem grandes diferenças entre suas execuções, agregando melhor aspecto qualitativo.

Para realizar a diferenciação dos conteúdos nos dois cursos, o professor $\mathbf{F}$ utiliza como premissa a compreensão de que a Licenciatura e o Bacharelado são diferentes. O aluno do Bacharelado precisa de uma especialização maior, deve ir direcionando ao longo dos semestres a sua formação para a área que deseja trabalhar, pois o campo de atuação é grande e, muitas vezes, exige conhecimentos mais científicos (ciências biológicas, do esporte). Já na Licenciatura ocorre o contrário, o professor de escola não pode ser especialista, deve estar preparado para atuar em todas as séries. Seus saberes estão ligados à área das humanas, garantindo uma compreensão maior sobre as necessidades dos alunos dentro do ensino básico.

Os saberes considerados essenciais, trabalhados nas disciplinas do professor, abrangem, no caso da disciplina de Bioética, a busca pelo entendimento dos motivos pelos quais são usados tais saberes nas universidades, bem como sobre as suas implicações para a vida pessoal e 
profissional dos acadêmicos. Na disciplina de História da Educação Física o objetivo é fazer com que os alunos compreendam que os fatos históricos não ocorrem sem um motivo aparente, tudo está ligado, pois as diferentes ações são inventadas pelos seres humanos que partem de necessidades, sejam elas econômicas, políticas ou sociais.

Mesmo que por diferentes vias, os professores B, C e F buscam desenvolver seu trabalho objetivando a formação cultural e política dos seus alunos, promovendo uma visão crítica de Educação Física sobre os jogos, esportes e suas funções dentro da sociedade, em detrimento das competências técnicas tão valorizadas em décadas anteriores no próprio CEFD/UFSM. Configura-se em um avanço significativo, pois a consolidação de novas teorias, dentro da referida instituição por intermédio de suas disciplinas, é o resultado de lutas e esforços históricos travados por profissionais da área. Esses esforços têm como finalidade superar o 'senso comum', amplamente difundido pela concepção tradicional e tecnicista, de que o esporte de rendimento é o principal objeto de trabalho do professor de Educação Física, principalmente daquele que atua dentro da escola.

Essas considerações são aprofundadas em estudo realizado por Castellani Filho (1998) que explora o conhecimento produzido em torno da dimensão cultural que envolve a Educação Física, ultrapassando as barreiras do simples exercício físico. Ainda, Bracht (1999, p. 81) lembra que:

\footnotetext{
Para realizar tal tarefa é fundamental entender o objeto da EF, o movimentar-se humano, não mais como algo biológico, mecânico ou mesmo apenas na sua dimensão psicológica, e sim como fenômeno histórico-cultural. Portanto, essa leitura ou esse entendimento da educação física só criará corpo quando as ciências sociais e humanas forem tomadas mais intensamente como referência. No entanto, é preciso ter claro que a própria utilização de um novo referencial para entender o movimento humano está na dependência da mudança do imaginário social sobre o corpo e as atividades corporais.
}

Quanto aos professores A, D e E constatou-se que eles não adotam uma concepção específica, em suas falas, destacam-se os métodos de ensino e o saber experiencial para organizarem as disciplinas. 
Eu não utilizo nenhuma abordagem específica! Eu acho que a minha metodologia é mais centrada no professor e não no aluno, ou seja, eu tenho o conhecimento e eu passo um conhecimento, às vezes eu digo que não sou um professor eu sou um palestrante. Eu faço algumas atividades com eles, mas as aulas são muito expositivas, a técnica que utilizo é de aulas expositivas com diálogos, algumas vezes com leituras discussão das leituras que cada vez me desmotiva mais porque os alunos não leem e comprometem o andamento [...] (Professor A).

Não tenho isso, acho que não! Até lembro que estudei isso, mas confesso que de fato eu não tenho um conhecimento disso para poder me situar, talvez eu até tenha uma identidade? Mas eu não saberia dar nome, porque realmente eu não saberia dizer. Talvez a metodologia que eu uso nas minhas disciplinas, nos dois cursos, tenha haver com abordagem! Eu trabalho com aulas expositivas, mas expositivas participativas. Ao mesmo tempo em que estou desenvolvendo o conteúdo questiono os alunos com a intenção que participem, trabalho com textos e artigos [...] (Professor D).

Eu não vou te dizer que eu sigo as teorias do Saviani, não! Eu procuro balancear isso, trazendo da minha experiência, como também, solicito que os alunos tragam as suas experiências para o desenvolvimento das aulas [...], eu procuro utilizar isso tanto na Licenciatura quanto no Bacharelado (Professor E).

De acordo com Libâneo (1994), os métodos de ensino são determinados pela relação objetivo-conteúdo, os quais condizem com os meios escolhidos pelos docentes para alcançarem os objetivos gerais e específicos. Englobam as ações realizadas pelos professores e alunos para atingirem as metas estabelecidas dentro da disciplina. Já os saberes experienciais também ganham um papel relevante em suas práticas metodológicas, segundo Tardif (2006) surgem como núcleo vital do saber docente, no qual os professores entrelaçam as relações exteriores com os saberes internos de suas práticas. Ou seja, o processo de ensino pode ser definido como uma sequência de atividade desenvolvida pelos professores, tendo em vista a aprendizagem dos 
conhecimentos e desenvolvimento de habilidades, proporcionando meios de assimilação ativa dos conhecimentos (LIBÂNEO, 1994).

Os professores A, D e E relatam que a maneira de trabalhar os conteúdos são os mesmos para a Licenciatura e o Bacharelado, a diferenciação que ocorre está em torno do contexto em que a atuação profissional irá ser desenvolvida. Por serem disciplinas predominantemente teóricas e com as bases de conhecimentos muito próximas entre os dois cursos, os exemplos utilizados em cada um dos ambientes de trabalho são os principais meios de diferenciação.

O professor A considera essencial que o aluno finalize a graduação, capacitando-o a desempenhar o seu papel dentro da Educação Física. Demonstrando competência na escola ou fora dela, ser um profissional diferenciado para que o trabalho realizado seja reconhecido pela sociedade. Ter domínio do conhecimento específico sem esquecer-se de estabelecer relações amplas com o contexto que está inserido. Para o professor D o importante é compreender os conteúdos desenvolvidos em sala de aula, utilizando-os com propriedade dentro do ambiente de trabalho, como também, é relevante que seus posicionamentos, em determinadas situações, como futuros profissionais, tenham um viés teórico que venha dar suporte a suas ações. Já para o professor E é importante utilizar toda a gama de conhecimento adquirida durante o período de graduação aliando os conhecimentos teóricos com as diversas experiências obtidas no curso, transformando-os em saberes que venham a auxiliar no desenvolvimento profissional dos alunos.

De um modo geral, os professores A, D e E direcionam o ensino para aquilo que Tardif (2006) denominada de saber-fazer, são as habilidades e competências para desempenharam as funções do ofício. Requer a união dos saberes, profissionais, disciplinares, curriculares e experienciais para servirem de base da prática docente. No entanto, percebe-se uma aproximação acentuada no que diz respeito às aprendizagens dos conteúdos que dependem de um conhecimento técnico e especializado, embora esses saberes sejam provenientes do conhecimento científico, são essencialmente pragmáticos, 
moldados para solucionarem problemas concretos, mas quando enfatizados em demasia, distanciam-se de uma formação vinculada à realidade do trabalho docente. Segundo Cunha (2010), através desse pressuposto, o conteúdo assume um valor significativamente maior do que o conhecimento pedagógico na formação de professores, legitimando-o como o principal saber desenvolvido na prática dos professores universitários.

\section{CONSIDERAÇÕES FINAIS}

Foi possível perceber nas falas dos entrevistados a utilização do saber experiencial como sendo um elemento fundamental em suas práticas de ensino. Através dele, são obtidos os princípios básicos para a organização do trabalho pedagógico dentro das disciplinas. Ou seja, ao compararmos as falas dos professores $\mathbf{B}, \mathbf{C}$ e $\mathbf{F}$, que adotam as abordagens pedagógicas, com a dos professores A, D e E, que não utilizam uma determinada concepção labordagem de Educação Física, vemos que, para estes últimos docentes, o saber experiencial aparece com mais frequência em seus relatos, o que indica maior importância do contexto da atuação profissional, já que esses professores não possuem uma fonte teórica específica que dê suporte as suas ações. Eles introduzem, a partir da exploração de diversas vivências, os objetivos a serem alcançados nas disciplinas. Em suma, fundamentam suas aulas em seus saberes experienciais.

Significa dizer que as atividades docentes, como todo trabalho humano especializado, requerem certos saberes específicos que não são partilhados por todo mundo. Isso permite que os professores embasem suas práticas num certo repertório de saberes típicos de seu ofício, os quais dependem intimamente das condições sociais e históricas que envolvem a profissão, passando pela sua organização, diferenciação, especialização, até os condicionantes objetivos e subjetivos que os professores lidam diariamente.

Sendo assim, à primeira vista pode parecer contraditória a associação do saber experiencial, que se caracteriza pela pluralidade de interações não dispondo de organização sistemática para a sua construção, com a ênfase dada pelos professores A, D e E sobre os saberes técnico científicos 
utilizados no desenvolvimento das suas práticas de ensino que, reconhecidamente, estão subordinados às concepções fechadas de conhecimentos teóricos. Observou-se que a relação ocorre a partir do momento em que a trajetória profissional desses professores está ligada a essa maneira de aquisição e transmissão de saberes, sendo refletida naturalmente dentro da atuação profissional.

Através de todas essas características apresentadas pelos professores, cabe ressaltar o que Libâneo (1994) descreve como sendo os procedimentos de ensino, componentes importantes que constituem os diferentes métodos empregados em sala de aula, correspondendo às ações específicas como (leitura de textos, experimentos, demonstrações) destinadas a potencializar a assimilação dos conteúdos. Também está relacionada com o que Tardif (2006) entende por saber-fazer, consistindo nos fenômenos ligados ao trabalho cotidiano relativo ao planejamento, organização e formas de desenvolver as aulas, englobando as atitudes e habilidades dos docentes.

Dessa forma, constatou-se que os professores utilizam os saberes curriculares para desenvolverem as suas atividades docentes, que apresentam-se na forma de programas, conteúdo e métodos que eles empregam em suas práticas pedagógicas. Ou seja, as falas indicam que os conteúdos sofrem poucas alterações em suas contextualizações para exemplificarem as diferentes aplicações em uma área ou outra, como também, adaptações em determinado momento da disciplina para contemplar os saberes previstos no cronograma de aula.

\section{CLAIRTON BALBUENO CONTREIRA}

Mestre em Educação pela Universidade Federal de Santa Maria (UFSM). Professor de Educação Física da rede municipal de ensino de Caxias do Sul (RS).

\section{HUGO NORBERTO KRUG}

Doutor em Educação e Doutor em Ciência do Movimento Humano pela Universidade Federal de Santa Maria (UFSM). Professor do Departamento de Metodologia do Ensino do Centro de Educação, do Programa de PósGraduação em Educação e do Programa de Pós-Graduação em Educação Física da UFSM. 


\section{REFERÊNCIAS}

ALMEIDA, M. I. Formação do professor do ensino superior: desafios e políticas institucionais. São Paulo: Cortez, 2012.

AZEVEDO, E.; SHIGUNOV, V. Reflexões sobre as abordagens pedagógicas em Educação Física. In: SHIGUNOV, V.; SHIGUNOV NETO, A. (orgs.). A formação do profissional e a prática pedagógica: ênfase nos professores de Educação Física. Londrina: O Autor, 2001. p.77-94.

BARDIN, L. Análise de conteúdo. Tradução de Luis Antero Neto e Augusto Pinheiro, Lisboa: Edições 70, 1977.

BOLZAN, D. P. V.; ISAIA, S. M. A. Pedagogia universitária e trajetória docente: relações e novo sentido da professoralidade. Revista Diálogo Educacional, Curitiba, v. 10, n. 29, p.13-26, jan./abr., 2010.

BRACHT, V. A construção das teorias pedagógicas da Educação Física. Cadernos Cedes, n. 48, p.69-88, ago., 1999. Disponível em:

$<$ http://www.scielo.br/pdf/\%0D/ccedes/v 19n48/v1948a05.pdf>. Acesso em: 12 abr. 2012.

CASTELLANI FILHO, L. Educação Física no Brasil: a história que não se conta. Campinas: Papirus, 1998.

COLETIVO DE AUTORES. Metodologia do ensino de Educação Física. São Paulo: Cortez, 1992.

CUNHA, M. I. Docência como ação complexa. In: CUNHA, M. I. (org.). Trajetórias e lugares de formação da docência universitária: da perspectiva individual ao espaço institucional. Araraquara: Junqueira \& Marin/CAPES: CNPq, 2010. p.35-48.

GODOY, A. S. Pesquisa qualitativa: tipos fundamentais. Revista de Administração de Empresas, São Paulo, v. 35, n. 3, p.20-29, mai./jun., 1995. 
GRILLO, M. Ação educativa e referência teórico-metodológica. In: ISAIA, S. M. A.; BOLZAN, D. P. V.; MACIEL, A. M. R. (orgs.). Pedagogia universitária: tecendo redes sobre o ensino superior. Santa Maria: UFSM, 2010.p.78-94.

HILDEBRANDT, R.; LAGING. R. Concepções abertas no ensino de Educação Física. 6. ed. Rio de Janeiro: Ao Livro Técnico, 2005.

HUBERMAN, M. O ciclo de vida profissional de professores. In: NÓVOA, A. (org.). Vidas de professores. 2. ed. Porto: Porto Editora, 1995. p.31-62.

KRUG, H. N. As abordagens pedagógicas da Educação Física. Caderno Didático: abordagens pedagógicas. Santa Maria: CEFD/UFSM, 2008.

LANKSHEAR, C.; KNOBEL, M. Pesquisa pedagógica: do projeto à implementação. Tradução de Magda França Lopes. Porto Alegre: Artmed, 2008.

LIBÂNEO, J. C. Didática. São Paulo: Cortez, 1994.

LUCARELLI, E. Pedagogia universitária e educação. In: CUNHA, M. I. (org.). Reflexões e práticas em pedagogia universitária. Campinas: Papirus, 2007. p.11-26.

MIZUKAMI, M. G. N. Ensino: as abordagens do processo. São Paulo: EPU, 1986.

NUNES, C. M. F. Saberes docentes e formação de professores: um breve panorama da pesquisa brasileira. Educação \& Sociedade, v. 27, n. 74, p.27-42, abr., 2001. Disponível em:

$<$ http://www.scielo.br/scielo.php?script=sci abstract\&pid= s0101-73302001000100003>. Acesso em: 26 jan. 2012.

PIMENTA, S. G.; ANASTASIOU, L. G. C. Docência no ensino superior. 4. ed. São Paulo: Cortez, 2012.

RAMOS, J. R. S. A semiologia e a Educação Física: um diálogo com Betti e Parlebas. Revista Lecturas Educación Física y Desportes, Buenos Aires, n. 20, p.1-10, abr., 2000. Disponível em: <http://www.efdeportes.com/efd20a/betpare.htm 
>. Acesso em: 20 out. 2012.

RIBAS, J. F. M. Praxiologia motriz: construção de um novo olhar dos jogos e esportes na escola. Revista Motriz, Rio Claro, n. 2, p.103-110, mai./ago., 2005. Disponível em: <http://www.periodicos.rc.biblioteca.unesp.br/index.php/motriz> . Acesso em: 15 nov., 2012.

RIBAS, J. F. M.; ARAÚJO, P. A. O ensino dos jogos esportivos coletivos e os universais de Pierre Parlebas: o exemplo no voleibol. In: MARIN, E. C.; GAMA, M. E. (orgs.). Aportes teórico-metodológicos: contribuições para a prática da Educação Física Escolar. Santa Maria: Universidade Federal de Santa Maria, 2008. p.77-94.

TARDIF, M. Saberes docentes e formação profissional. 6. ed. Rio de Janeiro: Vozes, 2006.

VEIGA, I. P. A. Docência universitária na educação superior. In: RISOFF, D.; SEVEGNI, P. (orgs.). Docência na educação superior. Brasília: Instituto Nacional de Estudos e Pesquisas Educacionais Anísio Teixeira, 2006. p.17-32. 